\title{
The Recovery Strategy of Rural Tourism in the Post-Epidemic Period
}

\author{
Jianchun Yang ${ }^{1,}$ Guifang Zhu ${ }^{2 *}$ \\ ${ }^{1}$ Guizhou University of Finance and Economics, Guizhou, China \\ ${ }^{2}$ Guizhou University of Finance and Economics, Guizhou, China \\ *Corresponding author. Email:17865153316@163.com
}

\begin{abstract}
The sudden pandemic COVID-19 has caused a huge impact on the rural tourism industry in the process of high-quality transformation and development. The outbreak and spread of COVID-19 not only exposed the shortcomings of the rural tourism industry, but also provided new opportunities for the future development of the rural tourism industry. Scientifically study the impact of rural tourism during the epidemic period and the development direction of rural tourism in the post-epidemic period, To propose targeted relief measures to revive the rural tourism industry, improve the mechanism of the rural tourism industry to respond to major emergencies, strengthen coordination with the government and industry associations, and promote the upgrade of the tourism industry under normal epidemic prevention and control. It is of profound significance to the recovery and high-quality development of rural tourism.
\end{abstract}

Keywords: COVID-19, Rural tourism; Post-epidemic period, Recovery strategy.

\section{INTRODUCTION}

The tourism industry is an externally sensitive industry that is often exposed to various risks and has been impacted by major emergencies more than once. For example, major emergencies such as the terrorist attacks of September 11 in 2001, atypical pneumonia in 2003, the tsunami in the Indian Ocean in 2005, and the Zika virus epidemic before the Rio Olympics in Brazil in 2016 have all caused severe damage to the tourism industry. The sudden pandemic COVID-19 has caused a huge impact on the economic systems of all countries. The development of COVID-19 is still in an uncertain stage, and epidemic prevention and control have entered normalization. At present, although the epidemic has been effectively controlled in our country, it still has not gotten rid of the impact of my country's economy. Rural tourism is the first to be hit hard in the affected economic sectors. Rural tourism can effectively integrate high-quality rural development resources, which is of great significance to the promotion of local economic development. It is an important force for the revival of traditional culture and an important carrier for rural revitalization. The impact of rural tourism during the epidemic period and the post-epidemic period are scientifically determined. The development trend of rural tourism, proposed targeted relief measures for the recovery of rural tourism, and perfecting the mechanism of rural tourism to deal with major emergencies are of great significance to the recovery and high-quality development of rural tourism.

\section{THE MACRO IMPACT OF THE PANDEMIC CONVIND-19 ON THE DEVELOPMENT OF RURAI TOURISM}

\subsection{Implementation of strategies not conducive to rural revitalization}

The report of the 19th National Congress of the Communist Party of China first proposed the implementation of the rural revitalization strategy. In 2021, the No.1 Document of the Central Committee further stated that the nation must be rejuvenated and the rural area must be rejuvenated. Rural revitalization is an important task for realizing the great rejuvenation of the Chinese nation. The countryside is a regional complex composed of the interrelation and interaction of humanities, economy, resources and environment. It has multiple functions such as production, life, ecology, and cultural inheritance. About $70 \%$ of our country's tourism resources are distributed in the countryside. 
Rural tourism uses rural natural resources and human resources can promote the integrated development of rural primary, secondary and tertiary industries and expand the path of rural revitalization. Tourism is a labor-intensive industry. Rural tourism can involve more people and increase farmers' sources of income. According to data from the National Rural Tourism Monitoring Center, 101 poverty alleviation monitoring sites (Registered poor villages) located in 25 provinces (districts and municipalities) throughout the country have eliminated 4,796 people from poverty through rural tourism, accounting for $30.4 \%$ of the poverty alleviation [1]. The impact of the pandemic COVID-19 on the tourism industry in 2020 has brought the tourism industry into a freezing period, which will reduce farmers' income from the tourism industry, may cause some of the population to return to poverty, and increase the difficulty of rural revitalization.

\subsection{Implementation of strategies not conducive to rural revitalization}

In recent years, my country's economic growth has slowed down. Due to the impact of the pandemic COVID-19, the economy will even experience negative growth in the first half of 2020. At present, my country's economic structure has changed from investment-driven to consumption-driven, and consumption has become an important driving force for my country's economic growth. Although the "troika" that drives national economic growth has been affected to varying degrees during the epidemic, consumption is the most affected. The direct impact of the pandemic COVID-19 on the economy is mainly concentrated in tertiary industries such as transportation, tourism, entertainment, and catering. According to data from the official website of the Ministry of Culture and Tourism, domestic tourism revenue in 2020 is 2.23 trillion yuan, a decrease of 3.50 trillion yuan or $61.1 \%$ from the same period last year. Urban residents spent 1.80 trillion yuan on travel, down $62.2 \%$; rural residents spent 0.43 trillion yuan on travel, down $55.7 \%$. The tourism industry is the leading industry of the tertiary industry, involving a wide range of areas and many cross-regional and cross-industry collaborations. Due to the linkage effect of the tourism industry, it will inevitably have a great impact on its upper and lower industrial chains and increase the downward pressure on the macro economy.

\section{THE MICRO-IMPACT OF THE NEW CROWN EPIDEMIC ON THE DEVELOPMENT OF RURAL TORRISM}

\subsection{Rural tourism enterprises are facing an existential crisis}

The tourism industry involves various subjects such as scenic spots, hotels, homestays, travel agencies, restaurants, and online tourism companies. The impact of pandemic COVID-19 on the domestic tourism industry in the short and medium term will inevitably affect the upstream and downstream industries of the tourism industry chain. During the worst period of the epidemic, major scenic spots and cultural and entertainment venues in the country were closed one after another, and various cultural and tourist activities were cancelled. The Ministry of Culture and Tourism Document No. 29, 2020, "The emergency notice on the suspension of business activities of tourism enterprises on the prevention and control of COVID-19" clearly requires travel agencies and online travel companies across the country to suspend group travel and "air tickets + hotels" Tourism products have greatly affected travel agencies and online travel companies. Tourism companies have launched cancellations in response to the country's call to reduce tourist flows. Almost every company needs to provide a huge amount of advance guarantee for the epidemic. Leisure, sightseeing, experience and other entertainment activities in rural areas have also been affected, especially the homestay has been severely impacted. Affected by the pandemic COVID-19, homestay orders are sharply reduced, encountered a large number of cancellations. For most homestays, in addition to rent costs, there are also fixed employee salaries and operating expenses. The operating pressure is greater, and there is great uncertainty about when the tourism business will return to normal. During the epidemic period, rural tourism small and medium-sized enterprises showed a cliff-like decline in their operating income, and the capital investment for normal operations of the enterprises could not be greatly reduced. They were faced with huge pressure, difficulties in operation, and even a crisis of survival when the capital chain was broken.

\subsection{Perception of travel risk affects tourists' willingness to travel}

Travel risk perception is the subjective judgment of tourists based on the characteristics and severity of specific risks. Risk perception will affect tourists' willingness to travel. According to assessments, major emergencies generally affect tourists' travel behavior within a period of time. For example, the outbreaks of SARS, H1N1 and Ebola have caused a certain degree of trauma to the tourism industry. The outbreak of the new crown epidemic has gradually evolved into a major media event and a global crisis. Major media around the world have rushed to report, which has enhanced tourists' perception of risks and greatly affected the tourism industry and the travel behavior of tourists around the world [2]. Psychological panic caused by the new crown epidemic, The worry will continue into the future, because when a tourist area is linked to a negative event or an increased risk of major events, tourists are more likely to change their travel plans to 
avoid what they think is "unsafe" travel destinations and seek safer options [3]. When tourists perceive a risk, it will not only affect their decision on where to travel, but first of all, whether they will travel or not. Although the pandemic COVID-19 has been effectively controlled in my country, in the future, due to safety considerations and media exaggeration, tourists' willingness to travel may be reduced due to increased perceived risks, and rural tourism will inevitably be affected.

\section{THE COUNTERMEASURES OF RURAL TOURISM IN THE POST-EPIDEMIC PERIOD}

As a "sub-production industry", the tourism industry is highly sensitive, but also extremely resilient and vital [4]. In the post-epidemic period, the tourism industry will inevitably face the predicament of recovery and reorganization, but the epidemic also provides new opportunities for the future development of the tourism industry and accelerates the process of high-quality development of the tourism industry. In order to effectively alleviate the impact of the pandemic COVID-19 on the tourism industry, there is an urgent need for the government, tourism companies, industry associations and other multi-dimensional subject contract cooperation to fully promote the recovery and revitalization of rural tourism in the post-epidemic period.

\subsection{The government actively guides and introduces supportive policies}

The restoration of industry confidence is inseparable from the support of the government. The danger of the capital chain being broken is the predicament of most rural tourism companies. Although the current epidemic has been effectively controlled and the tourism industry has ushered in an ice-breaking period, the rural tourism industry has returned to business as usual. A certain buffer period is still needed for the capital chain to be fully protected. In the post-epidemic period, the government must actively and quickly formulate effective supportive policies to help rural tourism companies tide over the difficulties. The government needs to flexibly formulate policies for the hierarchical classification of rural tourism enterprises. First, it must set up special support funds for enterprises to provide operating subsidies for enterprises, exempt some of the taxes for enterprises severely affected by the epidemic, and extend the period for taxpayers to reduce or exempt value-added tax. Second, we must lower the benchmark interest rate through the central bank, call on financial institutions to provide preferential loan support for enterprises, lower loan interest rates and loan thresholds, and reduce the losses of rural tourism enterprises and the pressure on tourism practitioners through financial and credit tools [5]. Third, Implement a salary protection plan for companies severely affected by the pandemic COVID-19 to stabilize employment. Fourth, the government must strengthen policy publicity and comprehensively publicize assistance policies, so that rural tourism enterprises should know everything about them, assist enterprises in enjoying these assistance policies, strengthen industry guidance and supervision, and promote the orderly resumption of work and production in the tourism industry. Guide, implement policies in different areas, make overall plans and take into account the prevention and control of the pandemic COVID-19 and the orderly operation of enterprises. Fifth, the government should improve the long-term mechanism for responding to emergencies and crisis management as soon as possible to minimize the impact of such major emergencies on the tourism industry.

\subsection{Innovative rural tourism business model}

After SARS in 2003, domestic e-commerce Taobao and Jingdong Mall rose rapidly. During the epidemic, online services such as live streaming, online education, and online office were very popular. It can be foreseen that the pandemic COVID-19 will also bring new consumption patterns. Produce some new formats. Under the impact of the epidemic, consumers have generated new demand for tourism, which also provides new opportunities for the business model of the tourism industry to update. For example, during the epidemic, some scenic spots use AR, VR and other technologies to develop online tourism products, and use new media technology to promote and display cultural heritage sites. Feel the magnificence of thousands of miles of rivers and mountains in the motherland immersively. From the perspective of the characteristics of "cloud tourism", it is not only applicable during the epidemic, but can also be promoted after the epidemic. Rural tourism companies can use the "cloud" to browse upstream and downstream, so that tourists can have a better travel experience in rural tourism destinations, and promote the integration of online services and offline entities; they can also use AR navigation as a part of rural tourism. Big features, to solve the problem of tourist routes in rural tourism, and make tourists' travel and leisure consumption more convenient, it can also develop smart ticket purchase, smart parking, smart official website, and face recognition through comprehensive applications of cloud computing and big data [6]. And other technologies to improve comprehensive service capabilities and levels. At the same time, rural tourism enterprises should innovate marketing methods, develop online promotion platforms, and use new network media such as Kwai and Weibo to promote rural tourism products. The single-dimensional development model of rural tourism that relies on natural scenery to obtain dividends has gradually declined. Innovative business models are imminent. It is necessary to cater to the development trend of the Internet, actively expand 
online tourism, enrich online service products, fully release tourism consumption potential, and drive tourism consumption upgrade, and then open up a broader space for rural tourism consumption.

\subsection{Industry mutual assistance and self-rescue, rebuild tourism consumer confidence}

In the post-epidemic period, Rural tourism companies should rebuild their confidence in tourism consumption. First, in response to the increasing uncertainty of many people's itinerary arrangements, the tourism industry needs to relax flexibility, providing sufficient protection to tourists, decreasing tourists' decision-making costs, strengthen corporate social responsibility, establishing a positive brand image, and attach importance to tourism promotion. On the premise of safe epidemic prevention and control, dispel tourists' worry about travel. The second is that rural tourism enterprises should increase revenue and reduce expenditures, reduce operating costs, and speed up the return of funds in special periods. Third, rural tourism enterprises must work hard to study the supportive policies issued by the government, whether it is the policies issued by various national ministries or local governments, including loan financing, government subsidies, and reducing the burden of taxes and fees [5]. Fourth, in addition to making full use of national policies, rural tourism companies should also strengthen their internal strength training, actively carry out tourism product upgrades, combine new market demands and consumption patterns, especially meet the needs for social distancing and health, and speed up tourism in the post-epidemic era. Innovation and upgrading of products. Finally, rural tourism enterprises must maintain adequate communication, gain the understanding and support of upstream and downstream industry chain enterprises, strengthen cooperation, give play to the self-reliance of the industry, create a "tourism enterprise community"[6], carry out mutual assistance and collaboration, cross-border joint actions, and establish an emergency crisis response mechanism and action framework for consultation, joint construction and shared responsibility.

\section{CONCLUSIONS}

After SARS, the domestic tourism market experienced a blowout phenomenon and China's tourism industry has entered a period of rapid recovery. Although many experts have assessed that the impact of the pandemic COVID-19 on the tourism industry far exceeds the influence of SARS, the basic development trend of the long-term improvement of my country's tourism industry will not change. Due to the epidemic control and the risk perception psychology of Tourists, the tourism recovery in the post-epidemic period will show the characteristics of near and far. The first to recover is the peripheral travel, followed by the province outbound and outbound travel. The pandemic COVID-19 has made people see the fragility of the rural tourism industry in the face of major emergencies, but also the problems and "internal injuries" in the development of rural tourism. Rural tourism companies should fully grasp the development trend of rural tourism in the post-epidemic period, paying attention to the changes in tourists' consumer psychology under the epidemic, use tourists' demand as the source of product innovation, and make full use of government policies through product transformation and upgrading, diversified operations to find a way out in the crisis, improve the risk management awareness of tourism enterprises, promote the upgrading of rural tourism industry under the normalization of epidemic prevention and control, and at the same time strengthen coordination with the government and industry associations to form a cooperative community to overcome the difficulties together [8]. Promote the restoration and revitalization of rural tourism, and promote high-quality development of rural tourism.

\section{ACKNOWLEDGMENTS}

This work was supported by the Fund Project: General Project of the National Social Science Fund "Research on the Mechanism and Path of the High-quality Development of Ethnic Village Tourism Leading Rural Rejuvenation" (No. 20BMZ128).

\section{REFERENCES}

[1] Wei Yan, Siping Yan. Impact of COVID-19 Epidemic on Tourism Development and Its Countermeasures [J]. Journal of Commercial Economics, 2020(11):190-192.

[2] Neuburger L, Egger R. Travel risk perception and travel behaviour during the COVID-19 pandemic 2020: a case study of the DACH region [J]. Current Issues in Tourism, 2020(5):1-14.

[3] COVID-19 and international travel restrictions: The geopolitics of health and tourism [J]. Tourism Geographies, 2020(2).

[4] Bin Dai. Impact of COVID-19 Epidemic on Tourism and Its Countermeasures $[\mathrm{J}]$. People's Tribune•Academic Frontier, 2020(06): 46-52

[5] Guoping Li, Yi Yang, Zhen $\mathrm{Xu}$, Tao Li. Comparative Study on Impact of Major Global Epidemics on Economic System and Its Response [J]. World Regional Studies, 2020, 29(06): 1091-1101.

[6] Xiuli Liu. Tourist Perception and Optimization of Rural Tourism Image Under the Guidance of $5 \mathrm{G}$ Technology [J]. Agricultural Economy, 2020(12): 140-142. 
[7] Zhiyong Chen, Fei Zhou. Fiscal Policy and Fiscal Reform Under the Downward Pressure of Economy [J] CAI ZHENG JIAN DU, 2020(19): $14-22$

[8] Junbo Shen, Tong Xu, Mingming Lu, Yanxia Zhai. Coping Strategies of Tourism Under the Impact of Epidemic and Its Development Trends in the Post-epidemic Period [J]. Macroeconomic Management, 2020(08): 55-60.

[9] Qingzhong Ming, Jianping Zhao. Impact of COVID-19 Epidemic on Tourism and Its Coping Strategies [J]. Academic Exploration, 2020(03): 124-131. 